\title{
REPROCESSING OF SHALLOW SEISMIC REFLECTION DATA TO IMAGE FAULTS NEAR A HAZARDOUS WASTE SITE ON THE OAK RIDGE RESERVATION, TENNESSEE \\ CONF-98
WASTE SITE
WNATESEE
}

William E. Doll, Environmental Sciences Division, Oak Ridge National Laboratơ, P.O. Box 2008, MS 6400, Oak Ridge, Tennessee 37831-6400; email: d8e @ ornl.goy

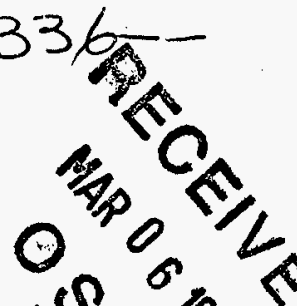

\section{ABSTRACT}

Shallow seismic reflection data from Bear Creek Valley on the Oak Ridge Reservation demonstrates that spectral balancing and tomographic refraction statics can be important processing tools for shallow seismic data. At this site, reprocessing of data which had previously yielded no useable CMP stacked sections was successful after application of these processing techniques.

\section{INTRODUCTION}

In 1992, shallow seismic reflection data were acquired along six profile lines (three of which formed a larger broken line) adjacent to the Bear Creek Burial Grounds, a hazardous waste site on the Oak Ridge Reservation, Tennessee (Figure 1). The data were acquired in an attempt to image faults and fracture zones that were thought to
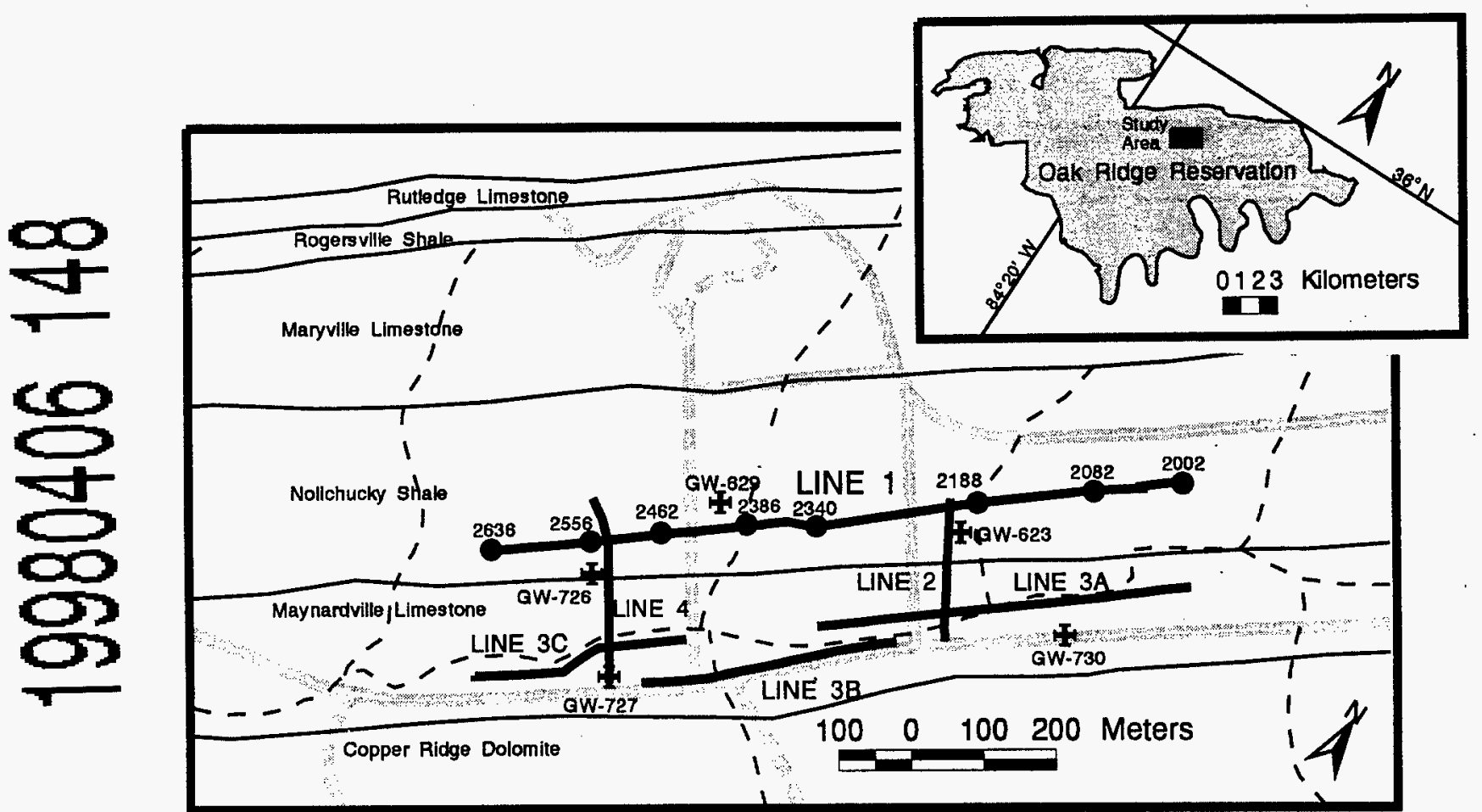

Figure 1. Map view of the study area. The inset shows the location of the study area on the Oak Ridge Reservation. Roads are shown as grey lines and streams are shown as dashed lines. Fine lines show geologic formation contacts which dip to the south at about $45^{\circ}$. The locations of five wells are identified by cross symbols. Common midpoint labels on Line 1 correspond to those on Figures 3-5.

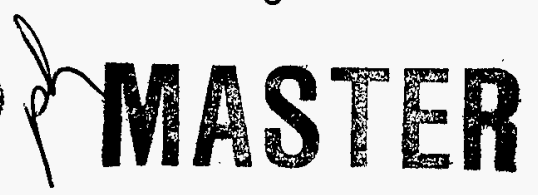

The submitted manuscript has been authorized by a contractor of the U.S. Government under contract No. DEAC05-96-OR22464. Accordingly, the U.S. Government retains a nonexclusive, royalty-free license to publish or reproduce the published form of this contribution, or allow

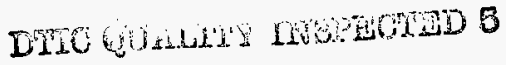




\section{DISCLAIMER}

This report was prepared as an account of work sponsored by an agency of the United States Government. Neither the United States Government nor any agency thereof, nor any of their employees, makes any warranty, express or implied, or assumes any legal liability or responsibility for the accuracy, completeness, or usefulness of any information, apparatus, product, or process disclosed, or represents that its use would not infringe privately owned rights. Reference herein to any specific commercial product, process, or service by trade name, trademark, manufacturer, or otherwise does not necessarily constitute or imply its endorsement, recommendation, or favoring by the United States Government or any agency thereof. The views and opinions of authors expressed herein do not necessarily state or reflect those of the United States Government or any agency thereof. 
occur in the vicinity and might serve as pathways for migration of dense nonaqueous phase liquids (DNAPLs) (Haase and King, 1990).

Initial processing of these data was attempted with a standard PC-based software package that was available at the time, but this failed to produce satisfactory images along any of the profile lines. The data were dominated by source generated noise, including guided waves (Robertsson and others, 1996), to the extent that no reflections could be clearly identified on shot gathers, and stacked sections indicated only a few weak reflections.

After successfully processing seismic reflection data from other sites on the Oak Ridge Reservation with a workstation software package, the Bear Creek data were reinspected, in the hope that some of the techniques that we had learned from processing other data sets could be used effectively on the Bear Creek data. In this paper, I shall present the results of the reprocessing that was done, and summarize the important elements of this work that could be applicable at other sites.

\section{DATA ACQUISITION}

Data were acquired during a 5-day period in July, 1992 by the Kansas Geological Survey (KGS) under the direction of Rick Miller. Acquisition parameters were selected on the basis of a series of walkaway noise tests that were conducted at the beginning of field operations. The two sources that were tested were the .50 -caliber downhole gun, and the KGS auger Gun. The auger gun uses a skid-steer loader-mounted hollow stem auger to fire blank 8 gauge shotgun shells at about $0.5 \mathrm{~m}$ depth. Both sources showed indications of weak reflections, and resulted in very similar data. The auger gun was selected for production data acquisition because it can achieve a higher rate of production, and because of safety concerns of site managers. Data were acquired at three-meter source and geophone group spacing. Three Mark Products L- $28 \mathrm{E} 40 \mathrm{~Hz}$ geophones, wired in series, were placed in a 1 meter in-line group at each receiver station to improve the signal-to-noise ratio. A Geometrics ES-2401X 48-channel seismograph was used to record $500 \mathrm{~ms}$ of data at $0.5 \mathrm{~ms}$ sample interval with a 500 $\mathrm{Hz}$ high cut acquisition filter and a $60 \mathrm{~Hz}$ notch filter. Weather conditions were uniformly warm with a few showers during the period of acquisition.

\section{DATA PROCESSING}

The unprocessed data are characterized by static problems and ground roll or guided waves (Robertsson and others, 1996) that mask the reflection energy (Figure 2a). Initial processing was conducted with 1992-era PC-based software. Frequency filters and frequency-wavenumber filters were used to try to reduce source generated noise. Static corrections were attempted by applying coherency filters to shot gathers that had been flattened by a linear moveout correction. None of these exercises resulted in identifiable reflections in the shot gathers, or in a satisfactory stacked section.

Subsequent seismic reflection profiling on the Oak Ridge Reservation was more successful (e.g. Doll and others in press, Liu and others, 1997, Carr and others, 1997). In a 1994 source comparison which was conducted about $7 \mathrm{~km}$ southwest of the Bear 
Creek site (Doll and others, in press), many strong reflections were imaged in data acquired with the same seismic source (KGS auger gun) in the same surface lithology (Nolichucky Shale). The 1994 data were sited in a different thrust sheet where the measured dips were about ten degrees less than at the Bear Creek site, and the water table was higher. Nonetheless, the contrast in these two data sets made the processing difficulties even more interesting and led to a series of attempts at reprocessing.

Processing of these data is still in progress. The most successful processing flow for Line 1 to date consists of:

1. Source and receiver geometry assignment

2. Tomographic refraction statics picking and inversion

3. Spectral balancing

4. Bandpass frequency filtering $(80 / 120 / 200 / 250 \mathrm{~Hz})$

5. Bad trace editing

6. First arrival mute (refraction and direct wave)

7. Surgical mute (air wave and ground roll)

8. Refraction statics correction

9. Common midpoint sort

10. Interactive velocity analysis and application

11. Normal move out correction and CMP stacking

12. Automatic gain control (100 ms)

Further improvements are expected from additional iterations in velocity analysis, further statics corrections, more careful editing and muting, and experimentation with a series of bandpass filters.

\section{Spectral whitening}

Figure 2 shows a comparison of two shot gathers with three different techniques for improving the spectral properties of the reflection energy. Figure 2a shows the raw data from these two shot gathers, dominated by low frequency noise, presumably ground roll and guided waves. A common way of enhancing the reflections is to apply a lowcut filter (Steeples and Miller, 1990). Figure $2 b$ shows the data from $2 a$ with a trapezoidal frequency filter applied $(85 / 120 / 200 / 250 \mathrm{~Hz})$. This reveals some narrow band reflections in Shot 105, particularly at about $0.3 \mathrm{~s}$, but does not yield any clear reflections in Shot 104.

An alternative to band pass filtering is to apply a technique known as "stretch automatic gain control" (SAGC), as described by Çoruh, 1985 and Doll and Çoruh, 1995. This method sharpens the reflections at $0.3 \mathrm{~s}$ and brings out reflections at $0.15 \mathrm{~s}$ as well on both shot gathers (Figure 2c). SAGC is applied by convolving each trace with a synthetic Vibroseis style sweep (8-seconds, $80-250 \mathrm{~Hz}$ upsweep in this case), to separate the frequency components of the original trace as a function of time. An automatic gain control is then applied to the stretched trace to equalize the amplitudes of the spectral components, and then the trace is cross-correlated with the synthetic 

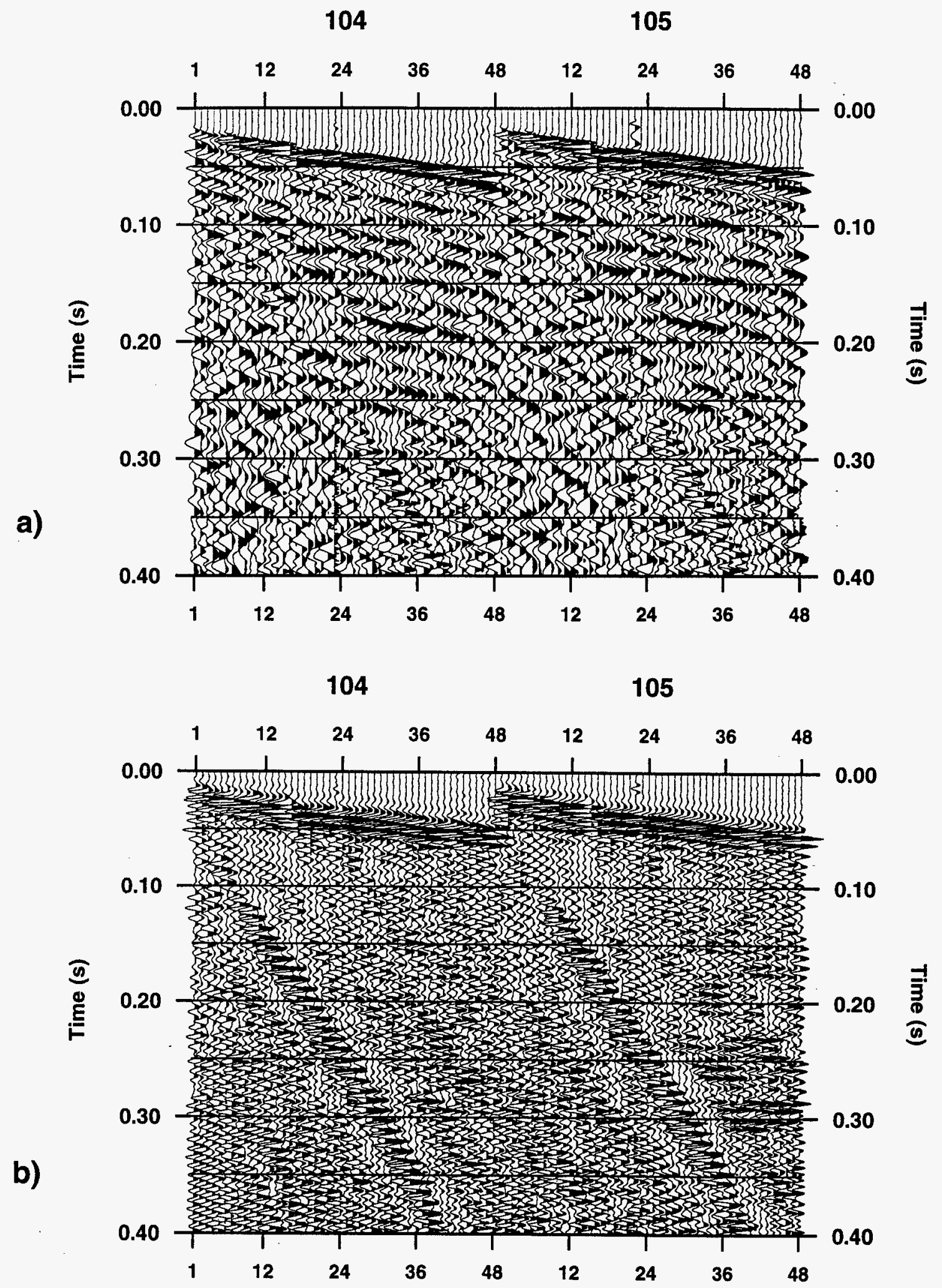

Figure 2. Comparison of spectral whitening techniques on two shot gathers. a) raw, unfiltered data, b) frequency filtered using a trapezoidal $85 / 120 / 200 / 250 \mathrm{~Hz}$ bandpass filter, 

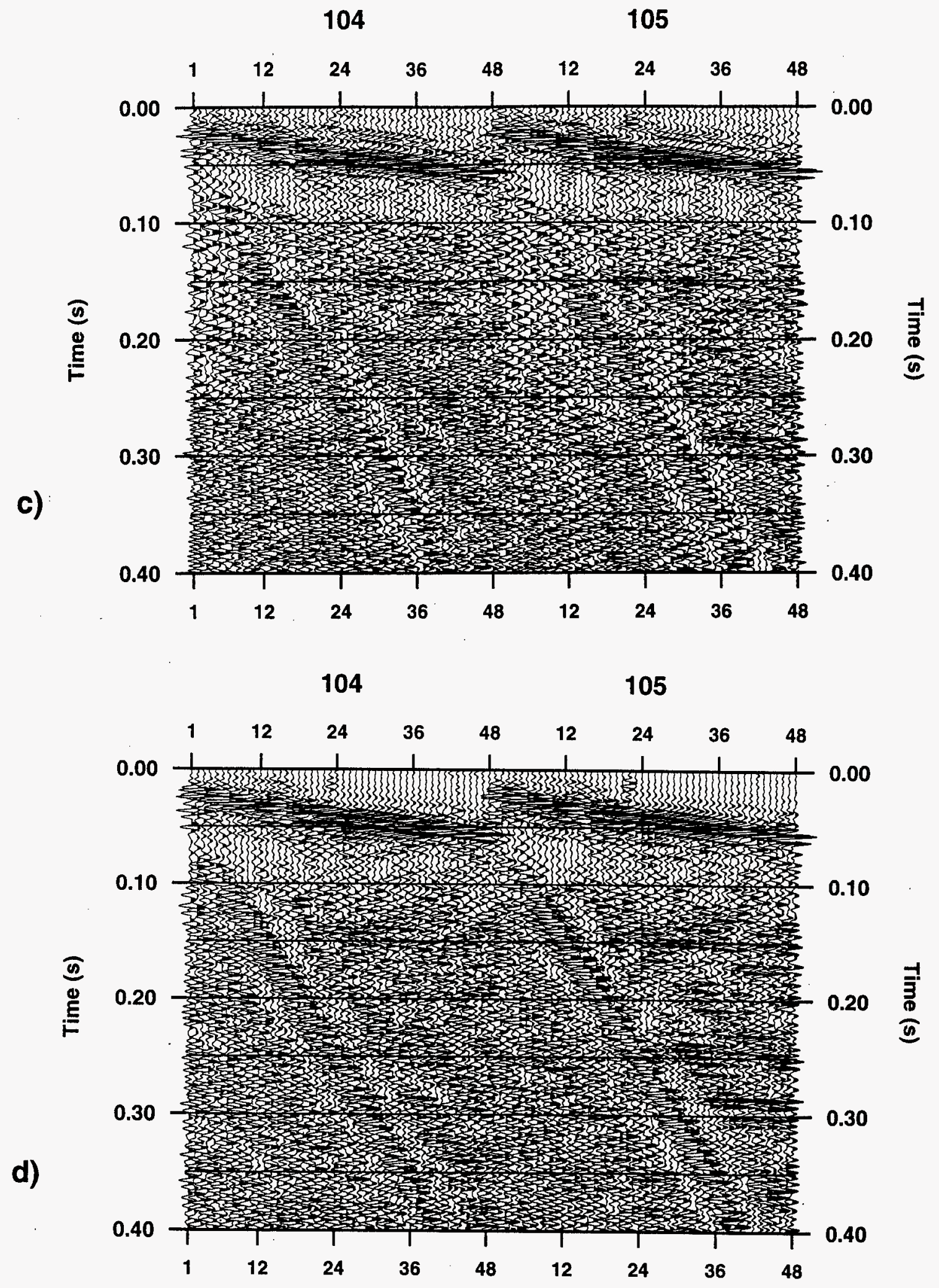

Fig. 2 cont. c) result from applying SAGC to the raw data, and d) output from spectral balancing. 
sweep to yield a spectrally whitened trace. It is an effective means of reducing ground roll and other source-generated low frequency / high amplitude noise because the spectral whitening is accomplished without making any assumptions about the reflected wavelet. Spiking deconvolution was also attempted with these data, but it did not produce satisfactory results because it requires that assumptions about the reflection wavelet be made from the data.

The spectral whitening technique which was most effective with these data is known as spectral balancing. In this method, the data are decomposed into spectral components over a series of narrow pass bands, and the amplitude at the midpoint of each pass band is used to calculate a scalar correction for that band. The pass bands are recomposited with the scalar corrections to achieve equalization over the spectrum of the data set. Here, I have used ten gates, $20 \mathrm{~Hz}$ each, from $40-240 \mathrm{~Hz}$. In the two shot gathers that are shown in Figure $2 d$, it results in enhancement of several reflections at $0.1-0.3$ s depth, particularly in Shot 105 .

\section{Refraction Statics}

Some of the shot gathers in the data set show irregularities in the first breaks due to variability in near surface conditions. Between CMPs 2000 and 2190, and between CMPs 2450 and 2636, the line was cut through undisturbed forest. Tree roots and a surface organic layer cause scattering and some energy loss. From CMP 2190 to CMP 2450 , the surface has been reworked due to development of the hazardous waste burial area to the north. First arrivals were picked on all shot gathers using an interactive routine included in the FOCUS (workstation DISCO) software package. These picks were then used in a tomographic inversion module in FOCUS to calculate refraction statics corrections for the entire line.

\section{CMP Stacked Sections}

Figures 3,4 , and 5 show common midpoint stacked sections for a portion of Line 1 , following the optimal processing flow, as well as for two alternative flows that demonstrate the importance of the two key processing elements for these data. The preliminary CMP stacked section which incorporates both spectral balancing and refraction statics and follows the flow listed earlier, is shown in Figure 3. When bandpass filtering is used instead of spectral balancing to whiten the spectrum, the resulting CMP stacked section is that shown in Figure 4. Although reflections can be seen between about 0.08 s and $0.3 \mathrm{~s}$, they are narrow band. When refraction statics are not applied to spectrally balanced data, the section shown in Figure 5 results. The reflection wavelets are sharper than when spectral balancing is not used, but they are more discontinuous and the reflections are more irregular than when both spectral balancing and refraction statics are used (Figure 3). Obviously, when neither of these steps are included in the processing flow, the CMP stacked section is poorer than any of those shown.

\section{SUMMARY}

Previous researchers (Steeples and Miller, 1990) have demonstrated that shallow 


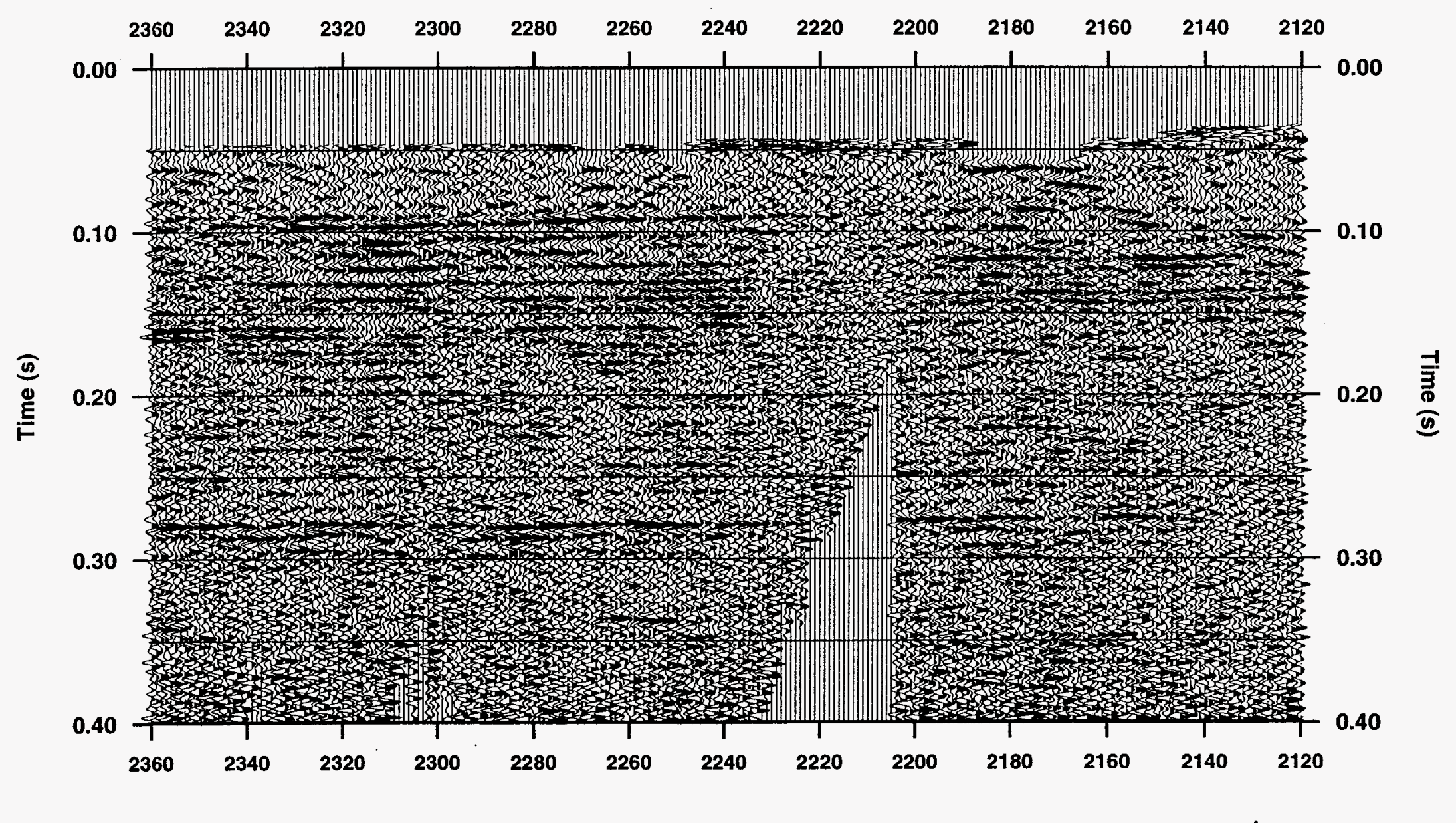

Figure 3. CMP stacked section for a portion of Line 1 using the 12-step processing flow that is listed in the text. 
Time (s)

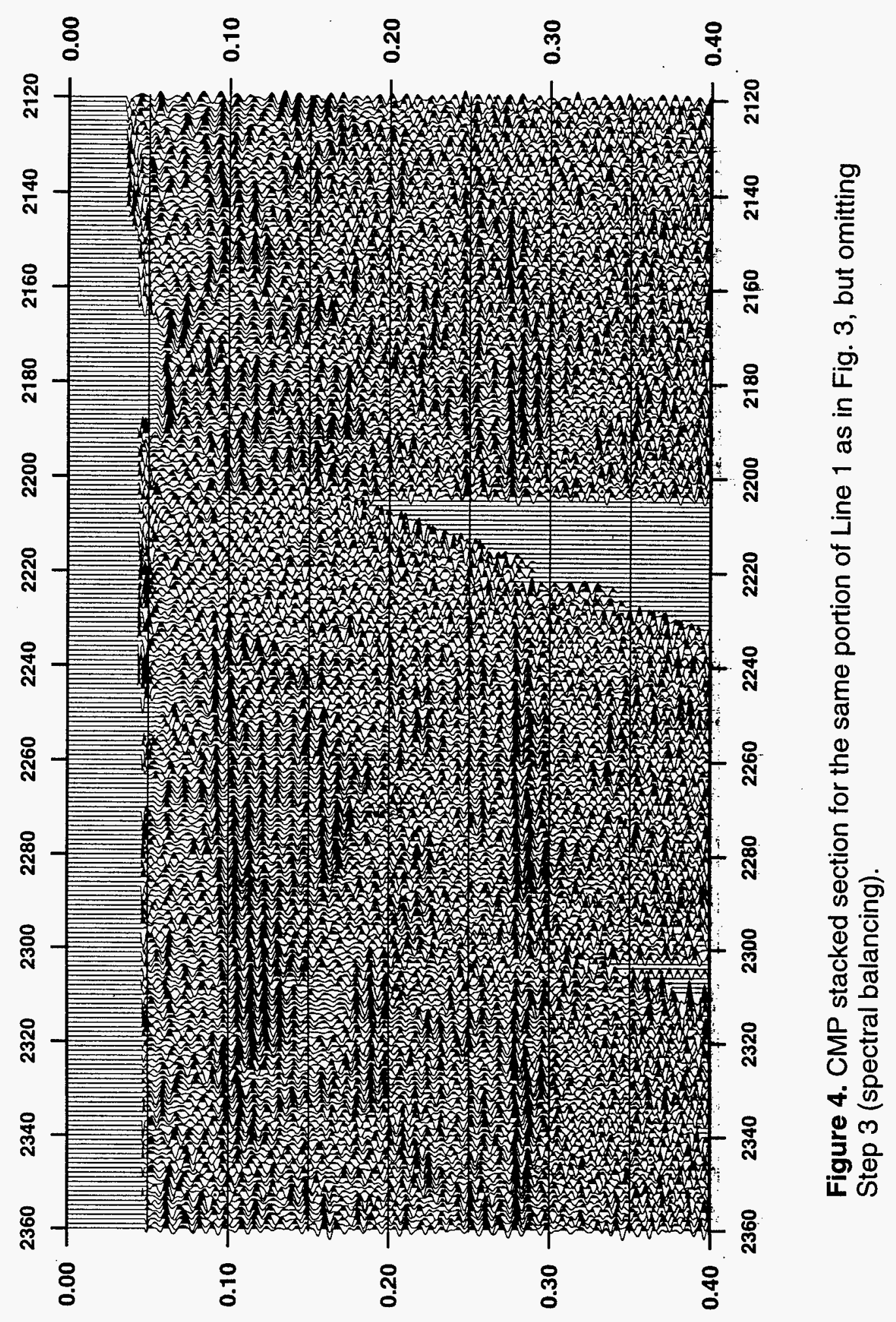

(s) әu!! 
Time (s)



(s) วu!! 
reflection processing requires careful monitoring at each step, and that many routines that have been developed for deeper applications cannot be applied to shallow data. The preliminary results shown here demonstrate that some of the more advanced routines developed for petroleum exploration applications are not only useful, but can make the difference between success and failure. The seismic data shown here, for instance, have been used in conjunction with rock core analysis to identify possible locations of faults that might serve as conduits for migration of contaminants from the site (Hollon, 1997). PC-based software has improved since the original processing of these data. Some of the newer releases have incorporated modules such as spectral balancing and refraction statics. Further research into the application and modification of "petroleum routines" to near surface seismic data could significantly increase the usefulness of and demand for shallow seismic imaging at environmental sites.

\section{ACKNOWLEDGMENTS}

I would like to thank the Kansas Geological Survey, particularly Rick Miller for acquiring the data that were used in this analysis. I also thank Brad Carr for providing insight into processing for these data. Funding for this work was provided by the $\mathrm{Y}-12$ Environmental Restoration Program. Oak Ridge National Laboratory is managed by Lockheed Martin Energy Research Corp. For the U. S. Department of Energy under contract number DE-AC05-96OR22464.

\section{REFERENCES}

Carr, B. J., W. E. Doll, and R. D. Miller, 1997, Near-surface seismic imaging and reflectivity studies of the Melton Valley waste areas, Oak Ridge Reservation, Expanded Abstracts, $67^{\text {th }}$ Ann. International Meeting., Soc. Expl. Geophy., 772-775.

Çoruh, C., 1985, Stretched automatic amplitude adjustment of seismic data: Geophysics, 50, 252-256.

Doll W. E. and C. Çoruh, 1995, Spectral whitening of impulsive and swept-source shallow seismic data: Expanded Abstracts, $65^{\text {th }}$ Ann. International Meeting., Soc. Expl. Geophys., 398-401.

Liu, Z., W. E. Doll and R. Young, 1997, Seismic reflection processing for characterization of a hazardous waste site: Proceedings of the 1997 Symposium on the Application of Geophysics to Engineering and Environmental Problems, p. 291-299.

Doll, W. E., R. D. Miller, and J. Xia, in press, A non-invasive shallow seismic source comparison on the Oak Ridge Reservation, Tennessee, Geophysics, v. 63.

Haase, C. S., and H. L. King, 1990, Work plan for the preliminary assessment and characterization of dense nonaqueous-phase liquids in the Bear Creek Burial Grounds hazardous waste disposal unit at the Oak Ridge Y-12 Plant, Y/ER-16, Oak Ridge Y-12 Plant, $16 \mathrm{p}$.

Hollon, D., 1997, The effect of fractures, faults, and sheared shale zones on the hydrology of Bear Creek Burial Grounds A-South, Oak Ridge, Tennessee, M. S. Thesis, Texas A\&M University, 222 pages.

Robertson, J. O. A., K. Hollinger, A. Green, R. Delaco, 1996, Effects of near-surface waveguides on shallow high-resolution seismic refraction and reflection data, Geophys. Res. Let., v. 23, 495-498.

Steeples, D. W. and R. D. Miller, 1990, Seismic reflection methods applied to engineering, environmental and groundwater problems, in Investigations in Geophysics, No. 5, Vol. 1: Geotechnical. and Environmental Geophysics, S. H. Ward, ed., p. 1-30. 


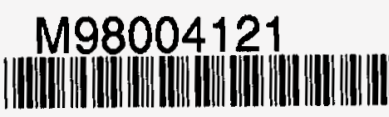

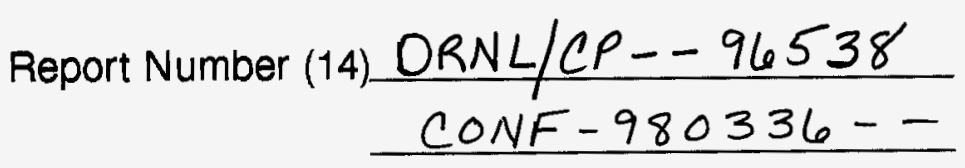

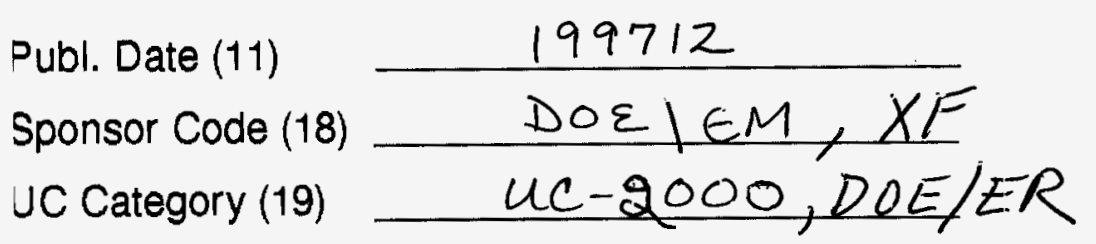

DOE 